\title{
Entrepreneurship and Music Technology Practitioners
}

This chapter will examine changes in the practice of record production, and the role of entrepreneurship as part of the skillset of the successful recording professional. In the recording studio, just as in every other sector of the music industry, change management (both technological and practice-based) has always been part of the ethos, and the successful development of the interfaces between amateur, semi-professional and professional activities is a vital part of this process. The recording industry itself has always demonstrated the effects of technological determinism ${ }^{1}$ in that developments in the technologies of recording and distribution have an active effect on the music itself. This has manifested itself right from the start, for instance in everything from the length of the average single, still at roughly 3 '45" as dictated by the size of the actual shellac (later, vinyl) record, to the effects of multi-tracking which frequently made a recorded song into a commodity object that was almost impossible to recreate live (Theberge, 1997, p.169). An understanding of the close relationship between creativity and future developments in audio technology is therefore vital to a studio professional.

The technical side of studio practice, in common with other areas of the music industry, is augmented by a combination of the practitioner's positive personality traits, their network, and luck. Aggestam summarises these as a 'harmonious set of skills' (2007, p. 32) that include 'intangible assets such as know-how' (Leadbeater and Oakley, 2001, p. 17). This chapter will, through case studies of two different informants, balance their experiences and opportunities to demonstrate some of the challenges that can be experienced within the recording profession, drawing across different life stories that include setbacks as well as situations that have contributed to positive career moves. These case studies illustrate different perspectives on the ways that entrepreneurship skills can be utilized in music production: one from a sole practitioner approach that demonstrates the integration of business and

\footnotetext{
${ }^{1}$ This term, coined by the American philosopher Thorstein Veblen who was active in the early $20^{\text {th }}$ Century, is used to describe the concept that technology controls humans, rather than the other way around.
} 
music-technology skills, and the other, from the supply of an adaptable and practical music engineering 'toolkit' to a mainstream commercial organization.

\section{Key Concepts and Issues}

Each of the case studies has been chosen to illustrate issues that the studio professional is likely to experience in the earlier stages of their career; one producer has set up her own fledgling music production business based on her activities as a cheerleader, and has been chosen to exemplify just how adaptable one needs to be at the micro level of practice. Chantal Epp's company, Synergy Sounds, illustrates the way that 'entrepreneurs are agents of change' (Leadbeater and Oakley, 2001, p. 11) as she utilizes the Internet not only to gather material but also to distribute her product. Her commercial activities reside firmly in the 'long tail' described by Chris Anderson, because she services a niche market that has a clearly delineated and possibly finite number of potential clients (Anderson, 2006, 2009). In contrast, the other interviewee, a recording engineer, uses herself as a resource, building a role for herself within the network of large commercial studios in the London area. Helen Atkinson is a more conventional studio engineer, but again, changes in the technology of recording mean that the niche she has created as a skilled live engineer allow her to engage in new forms of distribution, (direct from live to iTunes, for instance), and she uses entrepreneurial skills to capitalize on both her technological and her interpersonal experience.

Rapid changes in technology have added further opportunities and stresses to the practice of the studio professional, not only in the recording and mixing processes themselves but also in the methods of communication between artists, producers and engineers and of course, in distribution methods. Listening and consumption habits are in a constant state of flux as they have been since the invention of recording; notably, the globalization of the music industry facilitated by the Internet in the last 30 years has led to a rationalization of methods and aesthetics that could potentially temper the quest for innovation, currency and future proofing. As Prior observes: '...the ubiquity of digital technology is inseparable from the rise of globalization and the expansion of free-market capitalism increasingly reliant on rapid modes of 
communication'. (Prior, 2009, p 83). Negus discusses the 'chaos and disorder' of the music industry in the 1990s (1992, p. 151) and the 'conflict between commerce and creativity or art and capitalism (ibid, p. 152); add to this the acceleration of technological development, and the 'anticipatory approach' Negus describes is a vital part of survival. Recently, the quality expected by listeners has changed according to issues such as cheap portable listening on mobile phones, the subcultural capital factor of being a new vinyl collector and audiophile, and more recently, the desire of young bands to emulate their parents' record tastes (for instance, for rock bands like Led Zeppelin) that is causing the slow emergence of new analogue studio facilities to service this market $^{2}$.

An understanding of place is also essential, even in the age of globalization. Cultural clusters exist in physical form, sometimes in quite concentrated locations (often around defunct heavy-and light- industry locations such as redundant dockland areas- Leith in Edinburgh and London's East End, for example) and they exist parallel to a global Internet of opportunity (and competition). Local scenes, often encouraged by local and national regeneration funding, often combine music performance and recording venues, design studios, café, bar and club culture and other activities such as technological startups and craft activities, to form recognizable 'moments' of significant creative bursts. But scenes can also be diasporic in nature; these case studies demonstrate a shift away from defined locations and towards a wider networked community of clients that is held together by efficient use of communications technology.

As we shall see, the two producers interviewed here each exhibit different engagement with the internet: one depends on it not only for marketing, but also for content, as she has to constantly refresh the sources of the digitized music that she uses for her mash-ups. The other uses the net as a tool for sending her finished mixed and mastered products direct to iTunes, working on location 'in the box' (in this case, a laptop that captures live performances). Although at first glance, Chantal could be defined as a creative professional and Helen an expert facilitator, the activities of both of

\footnotetext{
${ }^{2}$ Issues discussed at the Art of Record Production Conference, Oslo, 2015
} 
them are more complex than this; Chantal's activities could be defined as postmodern: the redefinition of the meaning of existing music for a different purpose, thus creating a new artifact altogether. Helen's work is much more modern in nature: the acquisition of skills to service creative professionals. However, at the heart of the work that both of them do is a need to form social networks and a 'confident and committed view of the world' (one of Leadbeater and Oakley's definitions of the entrepreneur, 2001 p. 23). Computer technology is vital to both of them, and Chantal's business in particular illustrates what Hesmondhalgh identifies as a 'genuinely novel feature of the cultural industries since the 1980s', the fact that '...large and small companies are increasingly interdependent and mutually entangled in complex networks of licensing, financing and distribution' (2007, p. 301).

A young person entering Higher Education or indeed an apprenticeship, needs to possess a combination of skills, some of which may be self-taught, some peer-shared and some obtained from school or other less formal educational organizations. There can be a conflict between the ambitions of the individual and the practicalities of what is required by potential clients; just as in the artists' side of the industry, the concept of the star or the 'auteur' (Benjamin, 1936,1999) can be a driver for the individual producer to acquire new hardware, software, practical skills and most importantly, develop a commitment in terms of time that straddles the amateur/professional divide. ${ }^{3}$ For a producer who is used to working completely on their own and being in control of their output, it is sometimes difficult to adjust to the fact that from a business perspective being a supplier supercedes being a creative.

The realities of the employment market for any musician are extraordinarily tough, for not only is there a surfeit of well-qualified studio engineers and budding producers emerging from British universities and vocational courses every year, but there are also those who have entered the employment market via the more traditional apprenticeship route, plus selftaught producer/engineers operating at a subcultural level who achieve

\footnotetext{
3 See Finnegan, 2007, for an account of amateur music making that articulates clearly the fuzzy interface between amateurism and professionalism in a wide variety of musical activities in Milton Keynes.
} 
success via routes such as pirate radio and DJ-ing. In addition there is a simultaneous shrinkage of opportunity (for mid-range studios) and expansion of opportunity (for small-scale home production) afforded by the increase in laptop production (see Theberge,1997, pp. 231-235 and Wolfe, 2012). Also, of course, the collapse of the traditional structures of music selling that has been under way for the last 20 years has made the music industry jittery and averse to change.

However, as the first case study shows, it is possible to start up a viable business by combining a set of skills with a driving personality and an ability to respond to the needs of a niche market. Indeed, it is encouraging to find that there is still a need for a broad base of studio-related skills that is serviced mainly by adaptable people who have branded themselves as specialists.

This may at first appear to be a conundrum, but I have found that the focus of the specialist often needs to be backed up by change-management and broad-based skills such as patience, reliability, ability to juggle work commitments to prioritize urgent work without losing smaller clients (who may become bigger clients in time), and the ability to cross hardware and software platforms with ease. This is essentially a 'Say yes to everything' mentality that is demonstrated, for instance, by the successful mastering engineer Mandy Parnell's willingness to transport a portable mastering kit to Iceland in order to re-master Bjork's Biophilia album at short notice and at speed, sometimes working 36 hour days in order to complete the work by the deadline ${ }^{4}$.

Entrepreneurial activity is essential to the development of the recording industry for many different reasons; recorded music is the soundtrack to so many human activities; it is generation-specific, culture-specific and genderspecific. It provides both cultural capital (Bourdieu, 1973) and subcultural capital (Thornton after Bourdieu, 1995), and it is often at the margins of music production where budding entrepreneurs are active and that innovation and experimentation occur. Leadbeater (1999, p. 23) cites the frequency with which cultural entrepreneurs in general dedicate themselves to their activities without thought of financial investment, particularly at the outset (with the

\footnotetext{
${ }^{4}$ http://www.soundonsound.com/sos/jan12/articles/biophilia.htm
} 
accompanying problem of lack of capital, planning and manpower that can cause a small business to collapse). Opportunities can abound for those with good social skills and the 'radar' to recognize innovative music production technology that will have staying power in the future; an ability not only to predict the obsolescence of studio equipment, but also simultaneously to recognize the value of the burgeoning interest in particular vintage sounds and practices allows the successful practitioner to surf the changes that keep the industry alive. For instance, at the time of writing, the recent resurgence of vinyl as a medium for carrying recorded material has led to a parallel need for genre-appropriate mastering techniques and equipment ${ }^{5}$; the clients also need access to a cutting facility and a specific approach to sleeve-design, packaging and distribution. An engineer with a good understanding not only of the different sonic identities of different music genres, but also the routes that the music will take from the studio to the listener, will be able to create a business opportunity from the umbrella of knowledge that they have assembled through informal networking and peer sharing. This type of through thinking used to be the domain of efficient managers, but is now part of the ethos of any studio practitioner as a key survival skill in the music industry.

However, as with any activity in the creative industries, the risk factors are high because the entrepreneur is dealing with an audience as their market. The tensions between production and consumption are exaggerated because the tastes and activities of audiences depend on so many different cultural factors (Hesmondhalgh, 2007 p. 36). Likewise, the industry itself is a 'web [sic] of working practices, dialogues and articulated relationships' (Negus, 1992 p. 154) that has to be negotiated often with a hefty dose of lateral thinking.

To summarise: the production side of the music industry has always been an area that has developed alongside rapid technological change. Experimentation and the development of new techniques are built into practice, and producers/engineers who are amenable to change and able to

\footnotetext{
${ }^{5}$ vinyl mastering needs a particular equalization process that is different to $C D$ or file mastering, because the bass response and other aspects of vinyl discs are more limited. See http://www.recordingmag.com/resources/resourceDetail/114.html
} 
follow seemingly random pathways between the client (the artist/record label) and the end user (the audience) swiftly, efficiently, decisively and with creative sensitivity, are more likely to thrive than those who possess an interest in audio for audio's sake.

\section{Case Studies}

The subject of the main case study in this chapter is the music producer Chantal Epp, who graduated from the University of Westminster's BA Commercial Music course in 2013. As a final year project, she developed a cheer-music company, Synergy Sounds, which has thrived since she left University. A cheer-leader herself, she was bedridden after a severe injury and could no longer take an active part with her team. Bored, she realised that there was no existing supplier of custom cheer music in Britain and she resolved to fill the gap in the market by starting her own company through which she actively created and produced the tracks to order for teams across the UK. She already possessed music technology skills and the means to source material for her mash-ups; added to her business acumen, and with time to think through the project, she turned a period of enforced inactivity to her advantage.

I asked Chantal to describe the unusual nature of the business she runs:

I was a cheerleader at university and I got injured. I was the captain of my squad at the time, at uni, and my coach said, 'Oh, why don't you do the music for the team, for the competition?,' I'd had some previous experience with a producer, l'd done some recording with him, so I had basic understanding of how the studio works, and just developed it from there. l've found a niche market for my work.

In terms of setting up the company, her role-model was her mother, who had set up her own dental practice and runs it as a successful business; she had worked for her mother for six years and learned many of the business skills that she needed from that experience. Encouraged both by her coach and by her music technology lecturer at University, Mike Exarchos ${ }^{6}$, who

\footnotetext{
${ }^{6}$ http://www.stereo-mike.com/
} 
developed her programming skills in the space of two months, she used the enforced isolation of recovering from her injury to practical effect.

She had initially proposed the cheer-music business idea to her coach, but he was not interested in following it up as part of his own business. Market research had shown her that there was a market for this genre of music; there were only two or three other companies producing cheer music in the UK.

The start-up costs were very low because she already had access to a laptop with music software installed on it, backup support from Mike and other lecturers at the University, and perhaps the most important commodity, ample time in which to learn the specific techniques she would have to use to create the music. Citing her own impatience as a key factor in the decision to 'go it alone', she decided to capitalize on the previous studio experience that she'd had not only in a recording studio but also as an intern in a music supervision company:

I did a couple of weeks with Matthew Marston who's a producer in Kingston, Surrey, and he taught me a little bit about ProTools. I just basically made some music, he recorded me and then I also learnt a bit about the production side. And I did some work with PRS and music licensing as work experience; I did a week of music supervision with Platinum Rye ${ }^{7}$. It was suggested that I could go into music supervision because there, I'm finding music that fits a brief.

Chantal still works part time, now at CueSongs ${ }^{8}$, a company co-founded by Peter Gabriel, where she is involved with music supervision, manages Youtube channels, and so on. Not only does this contribute to her own productions by allowing her to hone her skills at 'feeling' the music, but it also gives her access to a constant supply of new music to use in her cheer music mash-ups. She continues:

I like to create stuff that's different, not mainstream pop; I like everyone's mixes to be original, something where I can get instrumentals and acapella, and add the individual touch to it.

7 http://ukmusic.platinumrye.com/

8 http://www.cuesongs.com/ 
Chantal's interests at school had been focused on music, mainly classical, and an inspirational music teacher had encouraged her to apply to the University of Westminster's Commercial Music BA after 'A' Level because of her interest in the business side of the music industry. In many ways, she has created the ideal company to match her interests, and she feels a real sense of achievement as the business gradually builds and grows.

In this respect her music skills, ability to learn and interest in business make her approach to being a producer very much of the modern age. As an entrepreneur, she is aware that the landscape will be constantly changing and she will need to adapt accordingly. For instance, cheer leading is relatively new to the UK (although in the USA, where it originated, it is much more common) and so there are many more companies supplying music to the teams. She has a strong awareness of the potential future for her music:

In terms of the cheerleading industry itself, it's a massively growing sport in the UK, Canada, and all over the world; it's huge. Europe is very behind; It's [most popular in] America, and then Canada and then the UK - so Canada's three years behind America, we're five to seven years behind, and then Europe is ten years behind. I think there's definitely scope to expand into it. There are not very many cheerleading teams in Europe. That's what's so great about a niche market: they can only go to you because there are so few companies that provide what they need.

Within five years Chantal feels that she will have developed her business enough to meet the inevitable competition head-on. The growing popularity of the sport in the UK was demonstrated in 2013 by the broadcast of a TV programme by the BBC called 'My Team the Cheerleaders' ${ }^{\text {, }}$, and there is currently a campaign to make cheerleading an Olympic sport.

There is more to the company that pure business, however. Chantal has a strong identity as a composer/producer and there are frustrations at the focus on chart music that the teams demand in their mash-ups. She is at the mercy of what the teams want but has a strong desire to change this:

${ }^{9}$ http://www.bbc.co.uk/cbbc/shows/my-team-the-cheerleaders accessed 04/09/14 
There's a music company in America called Cheer Sounds ${ }^{10}$, who did this brilliant marketing on Facebook, so even people who weren't cheerleaders saw it. They made [an original] poppy kind of song advertising their business, which was basically like a cheer; it had the right tempo and the right length and it was really cool: 'We're Cheer Sounds, we make original music'. I think that might take off and the teams might want original music; I haven't heard any teams use a mix like that, yet. But it's still a new area.

More recently British teams have been featuring voice-overs that reinforce the team identity; again, Chantal is watching this trend to see where she should move in terms of her own aesthetic approach:

Back in December less than $50 \%$ of the teams had voice-overs and now there's probably $60 \%$, or maybe $70 \%$ of the teams starting to use them, so I assume that will grow and when that's run it's course something new will come in: and it'll be cool if it's something more original: like the team's own actual song, rather than a mash-up of [other] songs.

Chantal's customer base began locally to service her own university team, and then developed through a network of teams; by knowing the genre of music thoroughly because of her own active involvement with cheerleading, she is able to create tailor-made music for each client. There is a standardized tempo (with slight variations) of 145 b.p.m. ${ }^{11}$ and with a sonic style that she describes thus:

Highly energetic, dance-y, tons of sound effects... I mix different instrumentals together, underneath different acapellas of songs: a mash-up of eight to ten songs in one two-and-a-half minute track; each song has to be in a different section of the routine. I program my own drumbeats.

She has to work quickly and to order for specified competitions, and at the moment is developing the company by working at the lower levels of the sport; for this reason she markets her company as the lowest-priced in the

\footnotetext{
$10 \mathrm{http://www.cheersounds.com/} \mathrm{accessed} \mathrm{04/09/14}$

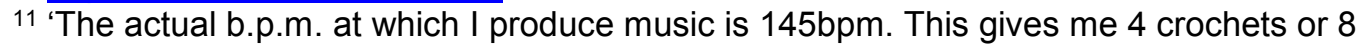
quavers to count to. Cheerleaders count in 8's. Routines are usually 47 counts of 8 and therefore meet the 2 minute 30 second requirement for competition. All music I deal with has to be time flexed in order to speed it up or slow it down'.
} 
genre. On the advice of the PRS, she obtained a license for the use of 1,000 tracks per year (which she can increase as the company expands); this allows her a lot of flexibility and is accepted by the PRS because the squads perform in established venues that are already licensed for the use of music ${ }^{12}$.

Social media is a vital marketing tool for her company. Normally

Chantal sends one tweet a day but in the competition season:

I just don't stop. Every single minute, every single team that competes, I will tweet. They then respond with: "Oh, Synergy Sounds just said something really nice about us!" or, "Oh look, we can get live updates about the competition that we're not at." So, then people can see what's actually happening at the competition - I'm like the news feed.

Post-competition, this can garner around 3000 views on the Twitter page and it is an efficient way of drumming up business. Another initiative that she has developed is a promotion for groups to get a free cheer mix, by entering a prize draw:

I've been tweeting constantly, every single day, asking people to enter their details on my website to potentially win a free cheer mix; all entrants will get $15 \%$ of any orders as an incentive. So even if they don't win, I can email them all in future.

This is all hard work; competitions sometimes run from 8 in the morning to 11 p.m. and Chantal travels all round Britain to sports arenas such as Birmingham NEC, Bournemouth BIC, and Telford International Centre.

Chantal's identification (above) of her mother's dentistry practice as a positive inspiration for her own company is interesting; Kariv (2013, p. 56) cites '.. a strong body of evidence that links entrepreneurs to parents who are themselves entrepreneurs.' and this is borne out here; Chantal, as a female producer, sees her mother as a role model; although she works in an entirely different area the advanced technical experience, networking ability and business skills of her mother's practice would have been very much to the forefront in her upbringing. She also acquired a lot of necessary business knowledge in part from online sources and partly through trial and error. A

\footnotetext{
12 IP problems can be a major difficulty for creative entrepreneurs, according to Rae. Overcoming these at the outset had, no doubt, a very positive effect on Chantal's ability to get her business off the ground. (see Rae, 2007:202)
} 
large bill from HMRC for National Insurance taught her to apply for an exemption, for instance; she cites making mistakes as a vital part of her learning process:

You freak out at first: "Why is this happening?" and then you learn the whole process after that. You just have to be willing to do your research, willing to learn, willing to hit dead ends, to make mistakes, to fail. Failing is the biggest learning curve of all; when you hit rock bottom the only way you can go is up, so you've just got to keep positive and go from there.

Chantal is also able to motivate herself and work completely on her own. During our conversation, she frequently referred to 'we', which led me to wonder if she was working with someone else. Unbidden, she explained later that as a sole trader, she is concerned that people should feel confident about what she is able to deliver. As a matter of professional practice, she hints at a larger operation behind her activities to encourage the confidence of her clients and she does understand that she will have to employ people in the future as orders increase.

Although an unusual facet of music production, Synergy Sounds follows a pattern that is common to the creative industries. The "cultural cluster' that Chantal finds herself in is unusually widespread physically and is held together and consolidated by the use of social media. The 'independent enterprises acting interdependently in complex and specialized ways' identified by Rae (2007, p. 56) combine amateur and professional activities that Chantal has been able to capitalize on through her insider's knowledge of cheerleading and the genre of music that accompanies it. This type of entrepreneurship, as Rae puts it, is: 'the intelligent application of skill' (ibid, p. 57). As well as being facilitated by Internet connectivity, Chantal's business has also been facilitated by the growth in home computer technology that has allowed her to participate in 'the creation of new subgenres and musical phenomena' (Anderton, Dubber and James, 2013, p. 83). There is also no doubt that as a female producer, the access afforded by a laptop has made her professional journey much less difficult (op.cit. Wolfe).

For a business such as Synergy Sounds, the integration of original music production into the 'world' of sports competition, itself straddling the 
fuzzy divide between the amateur and the professional, is both an advantage (the clarity of what is required and the fact that new, more up to date music is likely to be needed at regular intervals to ensure currency and variety) and a disadvantage (the increasing popularity of the sport will lead to more competition, especially from bigger companies that want to add the genre to their portfolio, and who have more robust promotion methods). Her nonmainstream business and its innovative use of the Internet illustrate Anderson's observations about the new ways of running a company in the $21^{\text {st }}$ century.

Long tail theory depends on two major factors: a feeling of optimism by the supplier, and the solvency of the purchaser. Anderson mentions his surprise at the aisles in the U.S. supermarket that are packed with unusual jams (2009, pp. 170-172); the manager tells him that they are very popular. To follow the analogy: can we then imagine the larder at home packed with the jars of dipped-into exotic jam past its sell-by date, with the simpler and more traditional flavours being regularly consumed and replaced? Niche markets are risky; they are not infinite, often depending as they do on volatile factors and (as Anderson observes), sometimes obscurity. In spite of the advantages of the Internet as a supply and marketing tool, small businesses still face common problems, summarized here by Rae:

\begin{abstract}
... finding and attracting their market to grow the demand for their businesses; attracting able people, financial and technical resources; making strategic choices on how to compete, collaborate and specialize in order to adapt to a changing environment; and, at a personal level, considering whether a long-term career in the creative industries is sustainable, since certain segments of these industries are dominated by fashion, taste and a young demographic (op.cit. p. 59)
\end{abstract}

To summarize, Chantal combines excellent sound engineering skills, an extensive knowledge of current musical trends, an awareness of the activities of the diaspora of cheerleading activities (from the UK to Europe, Canada, the USA and a growing enthusiasm in Japan), and up to date business and marketing skills, to work as a sole trader in music production for a niche market. After the initial idea her financial investment consisted of the 
purchase and maintenance of a computer and software, plus travel and accommodation; the time investment requires a degree of dedication and energy that is a common factor to entrepreneurs whatever industry they work in. ${ }^{13}$

In order to demonstrate that entrepreneurial skills and the essential work ethic that supports them have now become part of the role of any contemporary studio practitioner, even within more mainstream studio practice, the subject of my second case study is Helen Atkinson, an engineer at RAK Studios in St John's Wood, London. Helen is in her early 30 s and has frequently been self-employed; she has recently become a specialist in recording live broadcasts. Unlike Chantal, she did not go to University but instead entered the industry straight after school, and rather than servicing a niche industry on her own, she has entered a mainstream organization, albeit through branding herself as a specialist within that industry. In a different approach to that of creating her own business from scratch to cater for a niche market, Helen has negotiated her way through various roles as a sound engineer. She spent 18 months working at the residential studio Ridge Farm as a junior engineer, (where she was eventually replaced by a more senior engineer when business became more quiet) followed by a period of sending out hundreds of CVs to studios: 'Everybody that was listed in the Showcase book that I could get to within an hour or so in my car or by train'. She describes 'luck and good timing' as a factor in her opportunity to work at RAK; there was no identifiable 'big opportunity' that came her way, but an approach to work that she felt helped her:

Every client that you get on board and that wants to use you, you have to be aware of the opportunities that might come up and be open to giving something a go that's not necessarily within your comfort zone.

Helen persuaded RAK that they needed her as an in-house engineer at a time when they were exclusively employing freelancers; small things like making sure microphones had clips, screens were cleaned and that pianos

13 Time management is a major issue for everyone in the creative (and other!) industries. There is a roaring trade in time management literature: see for instance Forster, Mark (2006) Do It Tomorrow and Other Secrets of Time Management London: Hodder and Stoughton 
were returned to their rightful place were being overlooked: 'I made a role for myself here at RAK and then I made it so they needed me here, and I made it so that they've continued to need me here.'

Retained as a part-timer, she is also able to work freelance for the XFactor, creating mixes for iTunes of the Saturday-night live TV shows that go on sale at midnight the night after; she also records festivals for Abbey Road Live and recorded the sound at the $\mathrm{O} 2$ in London for the movie One Direction: This Is Us (Directed by Morgan Spurlock for Sony, 2013). One of the most useful skills that she says she has is the ability to read music:

I was in the school choir and things like that, so, I could read music, which isn't a key aspect of being an engineer, but actually people kind of like it, and they know that- it's another thing that means that you're more flexible, it means that they can put you on a string session where you might need to follow a score, or they could put you on an orchestral session. As a child, I had learned the Kodaly method for seven years, which I think gave me a great foundation in music.

Her training in classical music thus adds to the hinterland of knowledge that Helen brings to the job, potentially linking the cultural and subcultural capital aspects of music in a very practical way. 'Unseen' skills like this contribute to the smooth passage of cultural change, whether commercial or purely aesthetic and can pull a niche genre towards the mainstream. Rae cites the importance of cultural diffusion to the development of the creative industries in Britain, because of the

... deep-seated discontinuities in British life between 'the creative' and 'the mainstream' which stem from long-standing differences in cultural, educational, social and economic contexts and which affect interactions between the creative economy and the other constituencies. (2007, p. 54)

\section{Conclusion}

The flexibility of the digital world can facilitate a seamless route between creative activity and the market, repurposing digital information (seen here by Chantal's recycling of hit tracks into tailor-made mash-ups that 
perfectly match gymnastic routines), and marketing the resulting product through the same computer screen in a series of drags and clicks that can potentially send that product anywhere in the world in an instant. As a microentrepreneur, Chantal may find that she is challenged in future by what Leadbeater terms 'the missing middle' (1999, p. 12), the bridge between her 'one-[wo]man-band' company and the expansion and development necessary to survive against the inevitable competition. He comments that 'Businesses based on service provision often go through a period of feast, followed by a famine; they have been so busy delivering their current projects that they cannot find the time to sell new ones.' (ibid. p. 27). Will Chantal need to diversify as she expands the business? She plans to employ other people to take on aspects of the work that she does not enjoy so much, but the income needs to be there in order for her to make this commitment. Capital investment may become an option, but many entrepreneurs feel that this weakens the focus of their business and their direct connection with its products (ibid. p 23).

For both practitioners, social capital (another term coined by Pierre Bourdieu) is vital. The producer Richard Burgess summarizes his practice with the wry comment, 'Good connections are essential- you'll never see an ad for a record producer.' He continues: 'Job satisfaction is extremely high. [but] When you finally think you've got it all pinned down, reality intervenes to explain that the only constant is change'. (Burgess, 1997, p. 228) For Helen, the embracing of this change is embedded in a sense of teamwork:

I think it's probably one of those genuine industries where it really is a meritocracy and people don't come into work because it's regular or because they have to turn up every day; they want to turn up every day and work with a team that they like to work with, so, finding that team that you fit well with, personality-wise, skills-wise, that's really important.

In contrast, Chantal's sense of social context is forged through her embedded-ness in the sport that she provides a service to; for both, proactivity is a vital element in their self-management (Kariv, 2013, pp. 520522). Part of the charm of Chantal's business is actually the story behind it, which gives her as an entrepreneur a unique selling point; her practice is a 
logical development from the production methods described by Negus where the "entrepreneurial mode" meets the "art mode" in a collective-synthetic approach...'(op.cit. p. 88). The main difference between the two producers described above is the degree of risk that each of them faces; Helen is as good as her last project, but has a strong reputation in the industry as a reliable and talented engineer. Chantal responds to the 'chaos and disorder' that Negus identifies, and which is ordered to a degree by the Internet; but even Anderson admits that "... for the vast majority of us who live, work or play in the Tail, the cultural shift towards minority taste is already bringing a richer, more vibrant culture. How and when the money will follow is something that the next few decades will reveal.' (op.cit. p. 254); in other words, it is people's ability to buy niche products that wags the Long Tail.

Negus concludes that 'The music industry is not organized around mechanical inputs or outputs nor the linear transmission of products along a straight line from producer to consumer. The process is far less stable, riddled with fluctuations and bifurcations' (op. cit. p. 154). Internet distribution as described by Anderson is in reality a progressively much fuzzier shape than he would have us believe and of the two case studies one could conclude that Chantal's approach is the most risky of the two; but by remaining adaptable and positive, it is highly likely that both Chantal and Helen will continue to thrive as music producers in years to come. In their adaptability, they demonstrate a feature that has always been part of studio practice: willingness to experiment with new ideas and technologies. For instance, the demand for cheer music (especially in the UK) is a relatively new phenomenon; so is the demand for live versions of music from TV talent shows. New genres of music that evolve as a result of continuing developments in music technology and distribution systems are going to present new challenges for those entering the industry (as demonstrated by Synergy Sounds), but new practices and market demands are also evident in the more mainstream side (witness Helen Atkinson's time-pressured production of X-Factor tracks for iTunes). There are also other possible new routes of employment; for instance, the aforementioned need for specially tailored mastering, cutting and manufacturing processes for the growing vinyl market; or the digital archiving of back catalogue analogue material from 
record labels and existing public music archives such as the National Sound Archive which will require engineers not only skilled in shellac, vinyl and tape transfer, but also genre-specific listening and production skills. For stables of labels such as the Beggars Group, this is a commercially viable activity, which will result in increased sales of digital music. Funding for this process for public archives, however, will be at a premium and as such presents a challenge of its own; this could be a further development from the commercial audio activities described above; could an imaginative approach to funding by an entrepreneurial group of audio professionals 'corner the market' of what might prove to be a very long-lasting and potentially lucrative process ${ }^{14}$. There are undoubtedly unimagined future genres of, and purposes for, recorded music both mainstream and subcultural that will take the industry by surprise; in spite of the volatility of music audiences, we depend on the ideas, risk-taking and potential success of entrepreneurs to avoid stasis both culturally and economically. Niche activities provide a vital collective contribution to a differentiated cultural experience; as Anderson explains:

... we can now treat culture not as one big blanket, but as the superposition of many different threads, each of which is individually addressable and connects different groups of people simultaneously. (op.cit. p. 183-4)

\section{Bibliography}

Aggestam, Maria (2007) Art-entrepreneurship in the Scandinavian music industry, in Henry, Colette (ed.) (2007) Entrepreneurship in the Creative Industries: an international perspective Cheltenham, UK and Northampton, USA: Edward Elgar pp. 30-53

Anderson, Chris (2007) The Long Tail: how endless choice is creating unlimited demand London: Random House

Anderton, Chris, Dubber, Andrew and James, Martin (2013) Understanding the Music Industries Los Angeles, London, New Delhi: Sage

\footnotetext{
14 The National Sound Archive's estimate of the duration of this process was originally 15 years, and has now been revised to 42 years. Andy Linehan, speaking at 'Keeping Tracks: a one day symposium on music and archives in the digital age', British Library Conference Centre, $21^{\text {st }}$ March 2014
} 
Benjamin, Walter (1999) The Work of Art in the Age of Mechanical Reproduction in Illuminations, London: Pimlico

Bourdieu, Pierre and Passeron, Jean-Claude (1973), Cultural Reproduction and Social Reproduction in Brown, Richard K, Knowledge (1974), Education and Cultural Change: papers in the sociology of education London: Tavistock

Brown, Richard K, Knowledge (1974), Education and Cultural Change: papers in the sociology of education London: Tavistock

Burgess, Richard James (1997) The Art of Record Production London: Omnibus

Finnegan, Ruth $(1989,2007)$ The Hidden Musicians: Music-Making in an English Town Middletown, CT, USA: Wesleyan University Press

Forster, Mark (2006) Do It Tomorrow and Other Secrets of Time Management London: Hodder and Stoughton

Frith, Simon (1996) Performing Rites: on the value of popular music Oxford: Oxford University Press

Henry, Colette (ed.) (2007) Entrepreneurship in the Creative Industries: an international perspective Cheltenham, UK and Northampton, USA: Edward Elgar

Hesmondhalgh, David (2007) The Cultural Industries (2 ${ }^{\text {nd }}$ Edition) London: Sage

Kariv, Dafna (2013) Female Entrepreneurship and the New Venture Creation: an international overview New York: Routledge

Leadbeater, Charles and Oakley, Kate (2001) Surfing the Long Wave: knowledge entrepreneurship in Britain London: Demos

Leadbeater, Charles and Oakley, Kate (1999) The Independents: Britain's new cultural entrepreneurs London: Demos

Negus, Keith (1992) Producing Pop: culture and conflict in the popular music industry London: Edward Arnold

Prior, Nick (2009) 'Sampling, Cyborgs and Simulation: Popular Music and the Digital Hypermodern' in New Formations, No.66 Spring 2009 Chelmsford: Lawrence and Wishart pp 81-99

Rae, David (2007) Creative industries in the UK: cultural diffusion or discontinuity? in Henry, Colette (ed.) (2007) Entrepreneurship in the Creative Industries: an international perspective Cheltenham, UK and Northampton, USA: Edward Elgar pp. 54-71 
Theberge, Paul (1997) Any Sound You Can Imagine: making music/consuming technology Hanover and London: Wesleyan University Press

Thornton, Sara (1995) Club Cultures: Music, Media and Subcultural Capital London: Polity

Wolfe, Paula (2012) A Studio of One's Own: music production, technology

and gender. Journal on The Art of Record Production. accessed 11/11/14

http://arpjournal.com/2156/a-studio-of-one's-own-music-production-

technology-and-gender/

Web (all accessed 11/11/14)

http://arpjournal.com

http://www.soundonsound.com/sos/jan12/articles/biophilia.htm

http://www.stereo-mike.com/

http://www.synerygysounds

http://www.bbc.co.uk/cbbc/shows/my-team-the-cheerleaders

http://www.cheersounds.com/

http://ukmusic.platinumrye.com/

http://www.cuesongs.com

http://www.recordingmag.com/resources/resourceDetail/114.html

Thanks to Sarah Killick for transcription. 